\title{
Global environmental losses of plastics across their value chains
}

Ryberg, Morten W.; Hauschild, Michael Z.; Wang, Feng; Averous-Monnery, Sandra; Laurent, Alexis

Published in:

Resources, Conservation and Recycling

Link to article, DOI:

10.1016/j.resconrec.2019.104459

Publication date:

2019

Document Version

Peer reviewed version

Link back to DTU Orbit

Citation (APA):

Ryberg, M. W., Hauschild, M. Z., Wang, F., Averous-Monnery, S., \& Laurent, A. (2019). Global environmental losses of plastics across their value chains. Resources, Conservation and Recycling, 151, [104459].

https://doi.org/10.1016/j.resconrec.2019.104459

\section{General rights}

Copyright and moral rights for the publications made accessible in the public portal are retained by the authors and/or other copyright owners and it is a condition of accessing publications that users recognise and abide by the legal requirements associated with these rights.

- Users may download and print one copy of any publication from the public portal for the purpose of private study or research.

- You may not further distribute the material or use it for any profit-making activity or commercial gain

- You may freely distribute the URL identifying the publication in the public portal

If you believe that this document breaches copyright please contact us providing details, and we will remove access to the work immediately and investigate your claim. 


\section{Global environmental losses of plastics across their value chains}

\section{Morten W. Ryberg ${ }^{*}$, Michael Z. Hauschild ${ }^{1}$, Feng Wang², Sandra Averous-Monnery², Alexis}

\section{Laurent $^{1}$}

* corresponding author: moryb@dtu.dk

\section{Affiliations:}

${ }^{1}$ Quantitative Sustainability Assessment Group, Sustainability Division, DTU Management, Technical University of Denmark (DTU), Produktionstorvet, Building 424, 2800 Kgs. Lyngby, Denmark

${ }^{2}$ UN Environment, 1 rue Miollis, Building VII - 75015 Paris, France 


\section{Graphical Abstract}

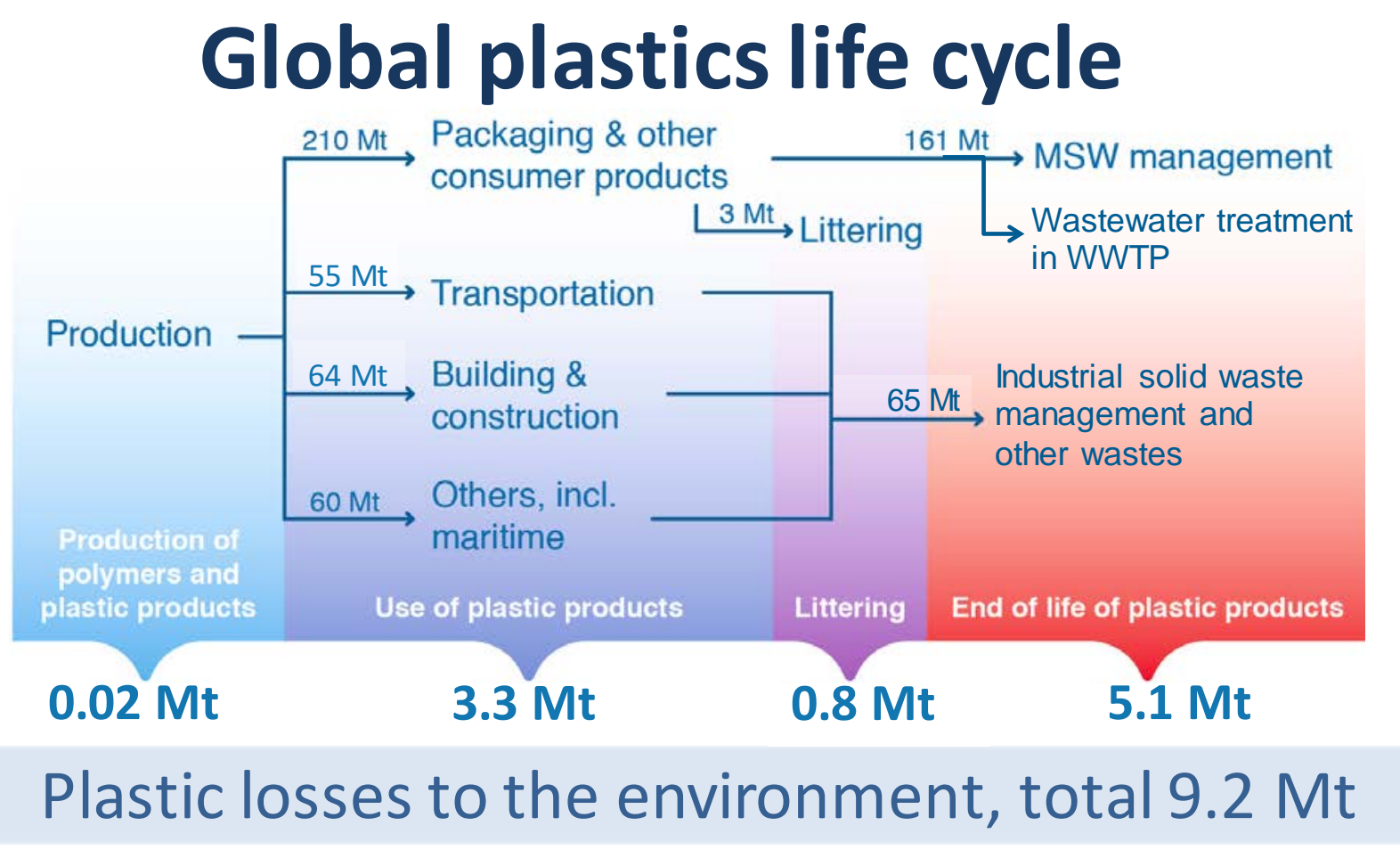




\section{Abstract}

With the increasing focus on marine plastic pollution, quantification of the environmental losses of plastics in the world, with differentiation into geographic regions, polymers and loss occurrences along the plastics value chains, is required. In this study, we make a global estimation of the losses of plastics to the environment across the entire plastic value chain, using existing literature and databases coupled with improved and additional methodological modelling of the losses. The resulting loss estimates are unprecedented in their detailed differentiations between polymers (23), plastic applications (13), geographical regions (11), and plastic value chain stages. Comprehensive sensitivity and uncertainty analyses were also conducted to identify key drivers in terms of plastic losses. We overall found that approximately 6.2 Mt (95\% confidence interval, CI: 2.0 - 20.4 Mt) of macroplastics and 3.0 Mt (CI: $1.5-5.2 \mathrm{Mt}$ ) of microplastics were lost to the environment in 2015. The major macroplastic loss source was identified as the mismanaged municipal solid waste (MSW) management in low-income and lower-middle income countries (4.1 Mt). For microplastics, the major sources were abrasion of tyre rubbers, abrasion of road markings and plastics contributing to city dust generation. To curb marine plastic pollution, such quantified mapping as ours are needed to evaluate the magnitude of the plastics losses to environment from different sources and locations, and enable a further assessment of their environmental damage. Through our uncertainty and sensitivity analyses, we highlight plastics sources that should be prioritized in further research works to obtain a more comprehensive and accurate representation of global plastics losses.

Keywords: Marine plastics; Microplastic; Macroplastics; Waste management; Plastics; Pollution 


\section{Introduction}

Marine plastic debris has been recognized as an environmental concern since the 1970s (Carpenter et al., 1972; Carpenter and Smith, 1972). Since then, an increasing number of studies and initiatives have brought the issue to public attention (Bonanno and Orlando-Bonaca, 2018; Borrelle et al., 2017; Haward, 2018; MacArthur, 2017; UNEP, 2016), to the extent that it has become an indicator to monitor our progress towards the United Nations’ Sustainable Development Goal No. 14 (United Nations, 2018). As a result of human activities, plastics are lost to the environment at different points across the plastics value chain (Boucher and Friot, 2017; Jambeck et al., 2015; Magnusson et al., 2016; UN Environment, 2018), from where they undergo transport and transformation processes (Horton et al., 2017) before reaching the marine environment and therein causing damages to marine biota (GESAMP, 2016). Marine plastics can generally be classified into macroplastics and microplastics (the latter including nanoplastics). Macroplastics are plastic pieces larger than $5 \mathrm{~mm}$ and microplastics are smaller (Arthur et al., 2009). Microplastics can be further subdivided into primary and secondary microplastics. Primary microplastics are intentionally manufactured to be less than $5 \mathrm{~mm}$ and used for specific industrial or domestic applications (GESAMP, 2015). Secondary microplastics originate from the breakdown of larger plastic items (either before or after entering the marine environment) through weathering of the plastic pieces from e.g. sunlight, wind, and water (Auta et al., 2017; GESAMP, 2015). Annual plastic production has grown almost exponentially, between 1950 and 2015, with a compound annual growth rate of $9.4 \%$ (Geyer et al., 2017) and losses of plastics to the ocean are projected to increase at similar rates unless actions are taken (Jambeck et al., 2015). Thus, an important focus of global and national actions is to prevent further plastic pollution in the oceans. 
An effective reduction of the ecological impacts of marine plastics should start with identification and quantification of the largest impacts from plastics in the marine environment and then trace them back to the human activities that are responsible for them (Bonanno and Orlando-Bonaca, 2018). Thus, a first step is to quantify the amounts of plastics entering the environment from different human activities. This need is echoed in the recent EU report "A circular economy for plastics” (Crippa et al., 2019) where knowledge on the sources of plastic losses to the environment from techno-economical systems is lacking. A number of studies have conducted material flow analysis of the plastics value chain (e.g. Geyer et al., 2017; Kawecki et al., 2018) with varying coverage and resolution of spatial and temporal scales, polymers, plastic applications, and plastic life cycle stages (production, use, end-oflife). Additional studies have also attempted to describe and quantify the sources and mass loss of plastics to the environment (e.g. Boucher and Friot, 2017 and Jambeck et al., 2015). However, all these studies have generally applied a narrow system scope by only including a subset of the global plastics value chain, e.g. only including parts of the world, specific polymers or only parts of the plastic life cycle. For instance, Jambeck et al. (2015) estimated losses of macroplastics to the marine environment from littering and mismanaged waste management for areas within $50 \mathrm{~km}$ from the coast and estimated global losses to the ocean to range from 4.8 to 12.7 million tonnes (Mt). Boucher and Friot (2017) quantified global losses of microplastics to the oceans and estimated an annual global loss between 0.8 and 2.5 Mt. Of this value, Boucher and Friot (2017) quantified losses from personal care and cosmetic products (PCCPs) to be around 0.03 Mt which is comparable to the study by Sherrington et al. (2016) which report a loss of $0.010-0.038 \mathrm{Mt}$.

Cole and Sherrington (2016) looked into quantifying pellet losses during plastic production and reported a loss of ca. 105 to 1054 tonnes of pellets are lost annually in the United Kingdom (UK) which is between $0.004 \%-0.040 \%$ of total UK plastic production (Cole and Sherrington, 2016). Moreover, 
the outflow of plastic debris from rivers has been estimated globally (Lebreton et al., 2017; Schmidt et al., 2017). Both of these studies found that a few rivers are generally responsible for the majority of riverine transport of plastics to the ocean primarily located in Asia. In terms of total plastic losses to the ocean, Lebreton et al. (2017) report that between 1.15 and 2.41 Mt of plastic waste enter the ocean from rivers while Schmidt et al. (2017) estimates an inflow to the oceans ranging from $0.47 \mathrm{Mt}$ to 2.75 Mt per year. Based on a combination of existing studies (e.g. Jambeck et al., 2015) and own estimates, Eunomia Research \& Consulting reported global plastic losses to the marine environment ranging from 6.5 - 22.6 Mt (Eunomia, 2016; Sherrington et al., 2016). However, specific information on the polymers lost and the sources of the losses was not presented. A number of national level quantification of plastic losses has also been performed. This has been shown for Norway (Sundt et al., 2014), Denmark (Lassen et al., 2015), Germany (Essel et al., 2015), and Sweden (Magnusson et al., 2016). These studies all provided a comprehensive overview of the sources of plastics lost to the environment. Across these countries, the main sources of losses were found to stem from inadequate waste management and use of plastic products or plastic containing products.

The goal of this study is to conduct a comprehensive estimate of plastic losses to the environment that is unprecedented in its coverage and differentiation between polymers, plastic applications, geographical regions, and plastics life cycle stages. This estimate builds upon some of the methods and sources used in previous studies, complemented with new ones, and further advance the estimates by using newer data and adding previously uncovered loss sources. The core of the methodological approach and preliminary results were reported in a UN Environment report (UN Environment, 2018), hence cross-references to that report are made throughout this study. However, the present study goes beyond the report on both levels of methodological approaches and results: it indeed includes additional sources of plastics losses, improving the estimates for a number of loss sources, deepens the 
discussion on the losses and strengthens the recommendations for further research to improve plastics loss mapping worldwide. Moreover, in the present study, a systematic sensitivity and uncertainty analysis was conducted to quantify ranges of plastics losses, identify the key parameters that drive plastic losses to the environment and on which focus should be laid on, and pinpoint the key uncertain parameters for which more research is needed in order to provide more accurate estimates and thus facilitate better informed decision-making for reducing marine plastic pollution.

\section{Methodology}

\section{$\underline{2.1 \text { Global plastic production and consumption }}$}

Plastics losses to the environment from the global plastics value chain, i.e. from production until final disposal, were estimated for the reference year 2015 (based on data availability). The estimate of global plastic mass flows for 2015 includes modelling global plastics production and consumption in 2015 and estimating global plastics waste management for 2015. The mass of plastic waste treated in 2015 is not likely to be equal to the mass of plastics produced in 2015 because a large share of plastics has a service lifetime extending beyond the year of production (UN Environment, 2018). Thus, a proportion of the plastic waste treated in 2015 has been produced in the years before. As a result of this, the plastic waste treatment was estimated independently of the plastics production and consumption.

To estimate global plastics production and consumption for year 2015, a fully linked model from plastic production to final use was developed based on statistical data on production and usage of plastics which was obtained from industry reports and scientific literature (see Supplementary Material (SM) Section 1). Information from the plastic industry was used for estimating global production as the plastic industry and plastic associations are likely to have the best and most comprehensive overview of 
Ryberg, M.W., Hauschild, M.Z., Wang, F., Averous-Monnery, S., Laurent, A., 2019. Global environmental losses of plastics across their value chains. Resour. Conserv. Recycl. 151. https://doi.org/10.1016/j.resconrec.2019.104459

global plastics production. About 322 Mt of plastics were produced globally in 2015 (PlasticsEurope, 2016a), excluding elastomers and synthetic fibers (e.g. PP, PET, and PA fibers). Indeed, global production increases to about 388 Mt plastics (UN Environment, 2018) after including fiber production (Credence Research, 2016; Maddah, 2016; plastemart, 2010) and production of elastomers (ETRMA, 2017, 2011). Table 1 shows the global mass production, its distribution between different polymers and the corresponding data sources.

Table 1. Global plastic production and share of total production, divided into different polymers. While not being defined as a 'plastic' fibers and elastomers, such as rubber, were included in this estiamte and are hereafter referred to as being plastics. Table is adapted from UN Environment (2018)

\begin{tabular}{|c|c|c|c|}
\hline Polymer & $\begin{array}{l}\text { Global production } \\
\text { [Mt] }\end{array}$ & $\begin{array}{l}\text { Share of total } \\
\text { production }\end{array}$ & Reference \\
\hline Polypropylene (PP) & 61.9 & $16 \%$ & (PlasticsEurope, 2016b) \\
\hline $\begin{array}{l}\text { Low density polyethylene, Linear low density } \\
\text { polyethylene (LDPE, LLDPE) }\end{array}$ & 45.7 & $12 \%$ & (PlasticsEurope, 2016b) \\
\hline Polyvinylchloride (PVC) & 43.0 & $11 \%$ & (PlasticsEurope, 2016b) \\
\hline High density polyethylene (HDPE) & 40.4 & $10 \%$ & (PlasticsEurope, 2016b) \\
\hline Polyethylene terephthalate (PET) & 18.8 & $5 \%$ & (PlasticsEurope, 2016b) \\
\hline Polystyrene, Expanded polystyrene (PS, EPS) & 18.8 & $5 \%$ & (PlasticsEurope, 2016b) \\
\hline Polyurethane (PUR) & 16.1 & $4 \%$ & (PlasticsEurope, 2016b) \\
\hline Other Thermoplastics & 10.8 & $3 \%$ & (PlasticsEurope, 2016b) \\
\hline $\begin{array}{l}\text { Acrylonitrile butadiene styrene, Acrylonitrile styrene } \\
\text { acrylate, Styrene-acrylonitrile (ABS, ASA, SAN) }\end{array}$ & 8.1 & $2 \%$ & (PlasticsEurope, 2016b) \\
\hline Polycarbonate (PC) & 2.7 & $1 \%$ & (PlasticsEurope, 2016b) \\
\hline Polyamide (PA) & 2.7 & $1 \%$ & (PlasticsEurope, 2016b) \\
\hline Elastomers (non-tyres) & 7.9 & $2 \%$ & (ETRMA, 2017) \\
\hline Thermosets & 33.7 & $9 \%$ & (prnewswire, 2015) \\
\hline Adhesives & 9.4 & $2 \%$ & (Grand View Research, 2015) \\
\hline Sealants & 1.8 & $0.5 \%$ & (Grand View Research, 2015) \\
\hline Coatings & 2.8 & $1 \%$ & (Sinograce chemical, 2017) \\
\hline Marine coatings & 0.5 & $0.1 \%$ & (Boucher and Friot, 2017) \\
\hline Road marking coatings & 0.6 & $0.2 \%$ & (Boucher and Friot, 2017) \\
\hline PP fibers & 30.1 & $8 \%$ & (Maddah, 2016; PlasticsEurope, 2016b) \\
\hline PET fibers & 18.8 & $5 \%$ & (Credence Research, 2016; PlasticsEurope, 2016b) \\
\hline PA fibers & 4.4 & $1 \%$ & (plastemart, 2010; PlasticsEurope, 2016b) \\
\hline Elastomers (tyres; mainly Styrene-Butadiene Rubber) & 7.1 & $2 \%$ & (ETRMA, 2011) \\
\hline Bioplastics (e.g. Polylactic acid) & 2.1 & $0.5 \%$ & (European Bioplastics, 2017) \\
\hline Total & 388.2 & $100 \%$ & \\
\hline
\end{tabular}

The global production and consumption of plastics was divided into 11 geographical regions (see Table S1). Global distribution of plastics production was derived based on production statistics and distribution of global consumption was based on statistics on per capita plastic consumption for each region multiplied with the population of the region (see Table S1). The current study distributed 
plastics into 13 plastic applications (see Table S2). The amount of plastics used in the different applications was estimated based on Geyer et al. (2017) but expanded to further differentiate between specific applications where more detailed statistical data was available and where further differentiation was considered important for the subsequent estimation of plastic losses related to the different application (see Table S3 for the specific amounts and references). For instance, the aggregated entity “Transportation” as used in Geyer et al. (2017) was divided into "Transportation - Tyres” and “Transportation - Others” based on information about polymers used for tyres from ETRMA (2011). Similarly, the category "Personal care products" was differentiated from that of "Consumer \& Institutional Products" based on specific data on "Personal care products" that we could retrieve (Boucher and Friot, 2017; Gouin et al., 2015)

The distribution of applications among the regions included in this study is given in Table S4 and the distribution of different polymers in terms of use in the different applications is given in Table S5. In total 23 different polymers were covered in this study. It was assumed that the polymers used in the different applications were equal across regions based on the assumption that the choice of plastics in an application is dependent on the specific application and not on the region.

Global plastics waste management for the reference year 2015 was modelled based on statistical information on plastic waste generation and treatment in 2015 (or nearby years depending on the availability of data). Most of the applications using plastics are considered treated as part of the municipal solid waste (MSW). This is the case for applications related to packaging, consumer \& institutional products, textile sector - clothing, and textile sector - others (UN Environment, 2018). A statistical model was developed for predicting annual per capita MSW generation based on 143 countries (covering 73\% of global population and including countries from all regions included in this 
study). This model was coupled with population weighted averages on the share of plastics in the MSW for each of the regions included in this study (see SM Section 1.3.1 for description) to estimate the annual amount of plastic waste generated as part of MSW. Using this approach, the annual generation of plastic waste in MSW was found to vary from 3.3 to $64.3 \mathrm{~kg}$ per capita across the regions in this study. On the other hand, adequate data on the region specific waste treatment was lacking for a number of application types, such as transportation and building and construction (see Table S6). For these plastic applications, only a single estimate on global waste generation was made and subsequent treatment and environmental losses are also only provided as global estimates. Estimates on the waste generation related to the plastic application denoted to as 'Other' (see Table S6) could not be estimated as information on the composition and treatment of this plastic is lacking. Thus, in accordance with Geyer et al. (2017) the waste generation was set to 38 Mt in 2015.

\subsection{Quantification of plastics losses to the environment}

Plastic losses were quantified for the sources presented in Figure 2 and the following section, briefly describes methods for quantifying losses of plastics to the environment. A more detailed description of the methods for estimating the losses from each source is given in SM Section 1.4.

Losses of plastic pellets during plastic production qualify as microplastics, as the plastic pellets are normally between 2 and $5 \mathrm{~mm}$ in size (PlasticsEurope, 2017). Studies quantifying losses during production and processing of plastics are generally scarce. Estimates on microplastic losses during production, processing, transport and handling were derived from three sources. Sundt et al. (2014) provided data for a Norwegian polystyrene plant where a loss of $0.4 \mathrm{~g} / \mathrm{kg}$ PS produced (i.e. loss of 0.04\%) was reported. Lassen et al. (2015) reported a loss of about $0.001 \%$ and Cole and Sherrington 
(2016) estimated an overall loss of $0.001 \%$ - 0.01\% from UK plastic processors (excluding losses from Transport and other facilities). It was assumed that plastics lost during plastics production will be transported together with wastewater with associated losses of plastics as given in Table S12 (UN Environment, 2018). Handling and transport of the plastic pellets was quantified based on estimates by Magnusson et al. (2016) and Cole and Sherrington (2016). Magnusson et al. (2016) report that losses should range from about $0.0005 \%$ and $0.01 \%$ while Cole and Sherrington (2016) report losses from $0.0003 \%$ to $0.003 \%$. The average value, i.e. $0.0035 \%$, was used for estimating the loss to the environment.

Losses during the use stage includes loss of macroplastic from littering where the plastics are e.g., being thrown away by the citizens and not treated as part of the formal waste management system (UN Environment, 2018). Studies on littering and the extent of littering are generally lacking which means that estimates on the loss of plastic from littering are very uncertain (Mehlhart and Blepp, 2012). Jambeck et al. (2015) estimated that that about 2\% of total mass of MSW generated was littered and about $25 \%$ of this waste was not captured during street sweeping, storm drain catchment, and pump station cleaning and, thus, lost to the environment. Other losses of macroplastic relate to ocean based activities such as losses of fishing nets and other fishing related fibers. Here, losses were based on values estimated by Boucher and Friot (2017) and UN Environment (2018).

Losses of microplastics related to use of cosmetics and personal care products (СРCP) were evaluated by developing a statistical model on the per capita consumption of cosmetics and personal care products [US\$/capita] as a function of per capita GDP [US\$/capita]. The model provided a relatively good fit with an $\mathrm{r}^{2}$ of 0.77 and allowed for estimating the distribution in consumption of CPCPs among regions (see SM Section 1.4.2). An equal distribution between costs of CPCPs and amounts of 
microbeads in the CPCPs was assumed (UN Environment, 2018). Moreover, it was assumed that all microplastics in consumed CPCPs will go to wastewater where capture and losses of microplastics will depend on the wastewater treatment for the specific region (see Table S12).

For washing of synthetic clothing textiles, about $2 \%$ of microplastics in clothing are lost via washing during the lifetime of the clothing (Boucher and Friot, 2017). UN Environment (2018) estimated that an annual consumption of about $25 \mathrm{Mt}$ of plastic fibres for clothing (Table S3), this amount to about $0.5 \mathrm{Mt}$ of fibres entering wastewater. Based on information about losses of fibres in wastewater (Table S12), the mass of fibres lost to the environment were estimated for each region (Table S17). In accordance with UN Environment (2018), the distribution of fibre types lost (i.e. PP, PET, and PA fibres) was assumed to be equal to the distribution in annual fibre production and consumption.

The estimate of losses related to tyre abrasion was based on Boucher and Friot (2017) which report that ca. $20 \%$ of the synthetic rubber in the tyre is lost over the tyre's lifetime. With an annual consumption of about 7 Mt of synthetic rubber for tyres (ETRMA, 2011) and assuming that the annual consumption is constant over time, an annual loss of $1.4 \mathrm{Mt}$ of microplastic to the environment has been estimated (UN Environment, 2018). Loss of plastics from abrasion of road markings are based on Boucher and Friot (2017) which state that about 0.59 Mt of road markings are used per year. With an estimated lifetime of about 1 year (Sundt et al., 2014), this gives an annual loss of $0.59 \mathrm{Mt}$.

Losses related to general dust generation in cities (collectively termed 'city dust') of which a fraction is plastics are scarce and only few studies have looked into the generation and composition of city dust and plastics as part of city dust (UN Environment, 2018). Information from national assessments (Lassen et al., 2015; Magnusson et al., 2016; Sundt et al., 2014) were used to upscale losses from national to global scale based on population data (Table S18; UN Environment 2018). Our estimate of 
city dust includes abrasion of exterior paints and coatings, road wear, shoe sole abrasion and household dust generation. For marine coating related losses, we apply a $10 \%$ loss of marine coatings over its lifetime in line with Boucher and Friot (2017).

The plastics end-of-life (EoL) stage is considered to be the stage where most losses occur (Jambeck et al., 2015) and plastics in the municipal solid waste (MSW) are considered more prone to being lost to the environment, while other types of waste, such as end-of-life vehicles (ELVs) or construction and demolition (C\&D) waste, are considered less important sources of plastic losses to the environment (see Table S19; UN Environment, 2018). For waste treatment, the current study includes plastics losses related to MSW, and losses from disposal of other applications (such as building industry and the transportation sector; see Table S6).

For MSW, as in UN Environment (2018), the following plastic waste fractions were modelled as being part of MSW treatment: packaging, electrical/electronic, consumer \& institutional products, and textiles (both clothing and others). Based on Jambeck et al. (2015), mismanaged waste was defined as all waste that is placed in dumps or waste that is landfilled in countries classified as low income countries by the World Bank. The share of plastic MSW send to landfills or open dumps was estimated based on data on MSW composition and treatment (Hoornweg and Bhada-Tata, 2012). Aggregation from national to regional level was done via population based weighted averaging (See Table S7 and UN Environment, 2018). Hoornweg and Bhada-Tata (2012) did not include comprehensive data on China and India. Thus, a mismanaged MSW share of 90\% and 32\% was used for India (Kumar et al., 2009) and China (Mian et al., 2017), respectively. Jambeck et al. (2015) assumed that between $15 \%$ and $40 \%$ of all mismanaged plastic waste (i.e. waste going to open dumps or to landfill in low-income countries) is lost to the environment. Although it may be realistic for direct littering, we considered this value to be 
overestimated for low technology landfills and open dumps (UN Environment, 2018). Thus, instead of $15 \%$, we preferably assumed a lower default value of $10 \%$ loss to environment from mismanaged plastic waste treatment. In this assumption, we factored in the likelihood that a significant fraction of waste from mismanaged landfills and open dumps remain within the facility, owing to general waste entrapment (piling of the waste preventing further escapes) and low-tech containment technologies, like mobile fences (Christensen, 1989), which reduce overall losses. An additional part is also likely to be picked up as part of general waste clean ups of inland areas or street sweeping to recollect some of the lost waste. Due to the uncertainty surrounding this value, we applied a wide uncertainty range for this value, with a $95 \%$ confidence interval (CI) ranging from $5 \%$ to $61 \%$ where the $97.5^{\text {th }}$ percentile of 61\% represents the average loss to the environment originally derived by Jambeck et al. (2015), who however chose to apply a more conservative range of $15-40 \%$ entering the oceans. For losses related to mismanagement of other plastic wastes such as the building industry and the transportation sector (see Table S6 for list), it was estimated that about 27.3 Mt of plastic waste is generated annually from building industry and the transportation sectors (Figure 1) (UN Environment, 2018). Yet, global or comprehensive regional estimates of the losses of plastic waste from e.g. disposal of end-of-life tyres and vehicles, C\&D waste, and industry waste could not be obtained (UN Environment, 2018). Indeed, there is a general lack of data on the amounts of these fractions which are being mismanaged. This is likely explained because mismanaged waste treatment of these fractions occurs as part of informal waste treatment, which is not part of international or national statistics. Thus, further research on the specific treatment of these applications, and the associated losses, are needed to find out if these losses contribute significantly to global losses of plastics to the environment. Still, as a means to account for the potential plastic losses during disposal of these fractions, it was assumed that the global share of mismanaged waste for these fractions can be approximated by that for mismanaged MSW (i.e. 25.5\% 
of global MSW, estimated as 41.0 Mt (Table S20) divided by 160.8 Mt (Table S7)). This is likely to be an overestimation because there is a larger potential for recycling (both formal and informal) of the plastic waste part of these fractions which is likely to be more accessible and purer than plastics in MSW. Hence, sensitivity of the total estimated plastic loss to this loss fraction was assessed as part of the sensitivity analysis. International trade of waste via imports and exports, in which the waste is treated in the waste management system of the importing country was included using the method described by Brooks et al. (2018). Here the UN Comtrade Database on the imports and exports of the category "plastic waste, parings, and scrap” was used to determine the net imports (i.e. import - export) for each global region of four polymer classifications: polyethylene (PE), polyvinyl chloride (PVC), polystyrene (PS), and others. The net imports were added to the generated MSW amounts and modelled as treated under the same circumstances as the MSW. The trade statistics do not cover informal or illicit trading, although these trading routes can account for a substantial share of total trade in a country, with reports as high as $80 \%$ of total trade for some goods (Jerven, 2014). In this study, the informal flows of traded plastics, which are not part of the UN Comtrade Database, were not included. This introduces an error to the estimate of traded plastics. However, the error is not propagated to the total mass of plastic waste generated and treated. Instead of being modelled as traded and treated in the importing region, the plastics are modelled as treated in the region where the waste is generated. Thus, the impact of the error is limited to only cover the difference in waste treatment rather than overlooking a potentially substantial fraction of the total mass of plastic waste. It was not possible to estimate losses of the plastic waste related to the 'Other' application as data on the composition and the specific applications of the plastics are lacking.

Loss of microplastics via application of wastewater sludge on agricultural fields was estimated by determining the mass of microplastics in wastewater which is captured in the WWTP (see SM Section 
1.4.2). The share of plastics and wastewater sludge applied on agricultural fields (i.e. 38\%; Table S13) and, thus, lost to the environment, was based on European statistics (Eurostat, 2018).

\section{$\underline{2.3 \text { Sensitivity and uncertainty analyses }}$}

The sensitivity of the total plastic losses to the environment relative to the specific model input parameters was evaluated by estimating normalized sensitivity coefficients $\left(\mathrm{S}_{\text {coef }}\right)$ for each continuous input parameter according to Eq. 1 (Ryberg et al., 2015; Yeh, 1986).

$S_{\text {coef }}=\frac{\Delta o u t}{o u t_{0}} / \frac{\Delta a_{k}}{a_{k, 0}}$

Eq. 1

Where $\mathrm{a}_{\mathrm{k}, 0}$ is the default input parameter value for parameter $\mathrm{k}$, Out 0 is the default model output calculated with the value of $\mathrm{ak}_{\mathrm{k}, 0}, \Delta \mathrm{a}_{\mathrm{k}}$ is the difference between the default input parameter and the perturbed input parameter, $\Delta$ Out is the difference between Outo and the Output calculated for the perturbed parameter value. All input parameters were perturbed by a 10\% increase. Table S23 lists the parameters that were used in the quantification of plastics losses presented in this study and also shows the estimated normalized sensitivity coefficients for each of the input parameters, of which the top-10 parameters are presented in Figure 5.

For the uncertainty analysis, the uncertainty of the results was quantified using Monte Carlo simulations using Vose ModelRisk version 5.3.8.9 (Vose Software, 2016). 10,000 runs were computed with variations of all parameters reported in SM Table S23 based on their defined probability distributions (see SM Table S23 for details). The results of the Monte Carlo simulations are given as the 95\% CI for the losses of plastics, expressed as total plastics losses, total macroplastics losses, and total microplastics losses (Figure 4). The contribution to variance of the input parameters to the total 
plastics loss was estimated as part of the Monte Carlo analysis (see Table S23) to indicate the importance of each input parameter in terms of the overall uncertainty of the plastic loss estimate.

\section{Results}

The overall mass flows occurring as part of the plastic life cycle are shown in Figure 1 (see Table S24 for disaggregation of the plastic mass flows at regional level). It shows that the majority of plastics are used for packaging and other consumer products (54\%), with the remainder of the plastics being used in other sectors such as construction, transportation, and industry. Consequently, the majority of the quantified waste generation also stems from consumer usage of plastics (as part of MSW) which was found to be $161 \mathrm{Mt}$ while littering was estimated to be about $3 \mathrm{Mt}$ in 2015. In comparison, the quantified mass of waste from non-consumer products was estimated to be $65 \mathrm{Mt}$ with $38 \mathrm{Mt}$ stemming from the 'Other' plastic application. Thus, the plastic in-use stock was found to increase by about 159 Mt in 2015. However, the change in in-use stock should be interpreted with care as data on waste generation is highly uncertain for a number of plastic applications and more knowledge about waste generation of plastics is generally needed. Global plastic losses to the environment was found to be 9.2 Mt in 2015 (Figure 1) with a distribution of 67\% and 33\% for macro- and microplastics, respectively (Figure 2). Across the plastics life cycle, the largest losses of plastics occur in the use and EoL stages, which account for ca. 36\% and 55\% of total plastics losses to the environment, respectively. Losses during plastics production are relatively small and account for $0.25 \%$ of total plastic losses. In general, about $90 \%$ of microplastic losses are related to the use stage and about $77 \%$ of macroplastic losses are from the EoL stage and 13\% of macroplastic losses stem from littering. 


\section{Global plastics life cycle}

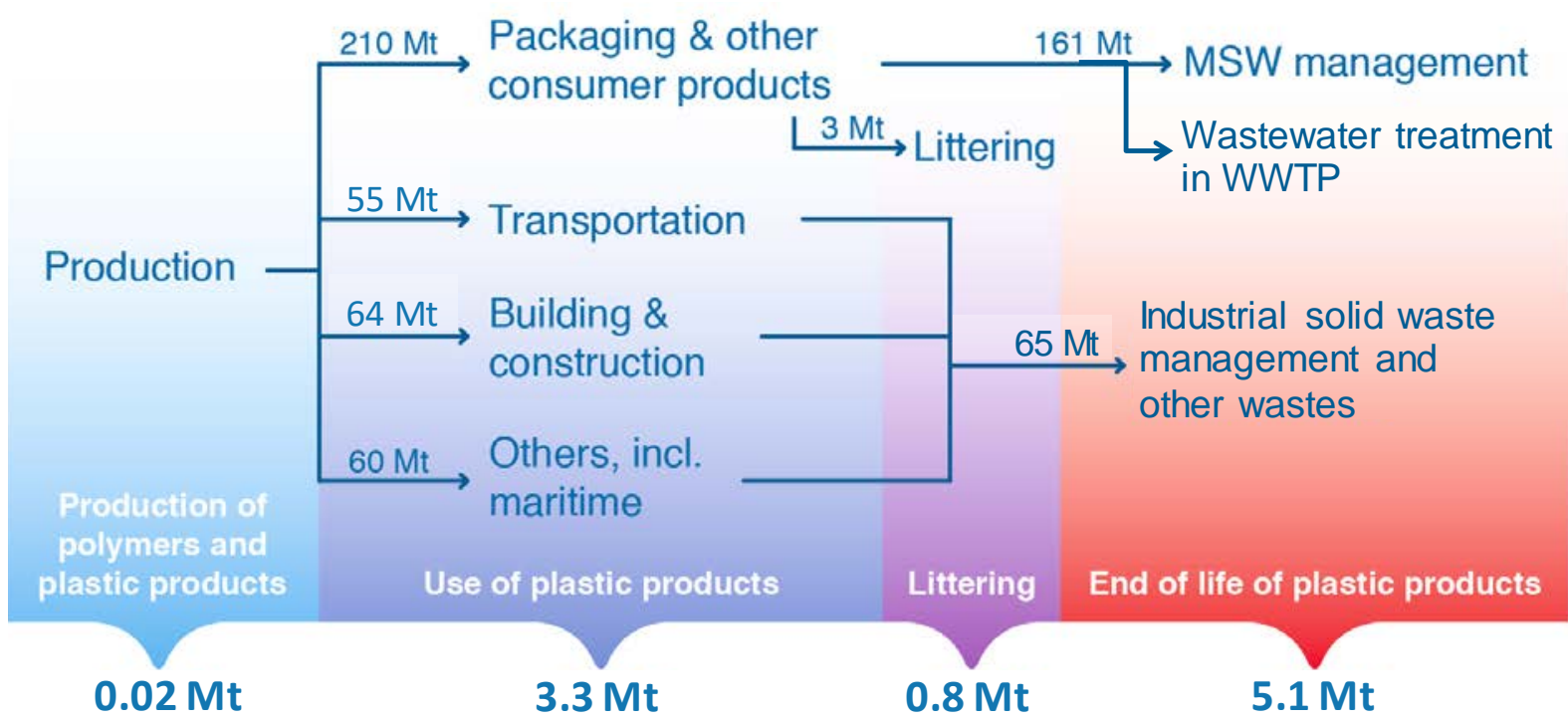

Figure 1 Global plastic value chain and estimated losses to the environment for the year 2015. Overview of the plastic value chain showing amounts annually produced, used in different sectors and eventually disposed of (end-of-life stage). Total masses of plastics lost to environment (marine, freshwater, and terrestrial compartments) are shown per life cycle stage. The mass of plastics produced is not equal to the mass of plastics disposed of due to plastic service lifetime extending beyond the year of production. Accordingly, a fraction of the plastic wastes disposed of in 2015 were produced in the years before 2015.

Figure 2 shows the plastic losses to the environment distributed into geographical regions, macro- and microplastics, and loss sources. Mismanaged waste management is responsible for the overall largest loss with the majority stemming from mismanaged MSW (4.1 Mt), like uncontrolled open dumping and landfilling (Jambeck et al., 2015) with the rest coming from mismanaged waste management related to e.g. the construction and transportation sectors. The largest losses of macroplastics during the use of plastic products is from littering ( $0.8 \mathrm{Mt})$ while $0.6 \mathrm{Mt}$ of plastics lost during use are related to marine activities, like lost fishing nets and ropes. The geographical distribution shows that losses of macroplastics predominantly stem from regions with a relatively large share of low-income countries and where open dumping of waste is done (e.g. Africa and Asia), but also as function of the share of plastics in the MSW such as Latin America \& Caribbean where ca. $11 \%$ of the MSW is plastics. 


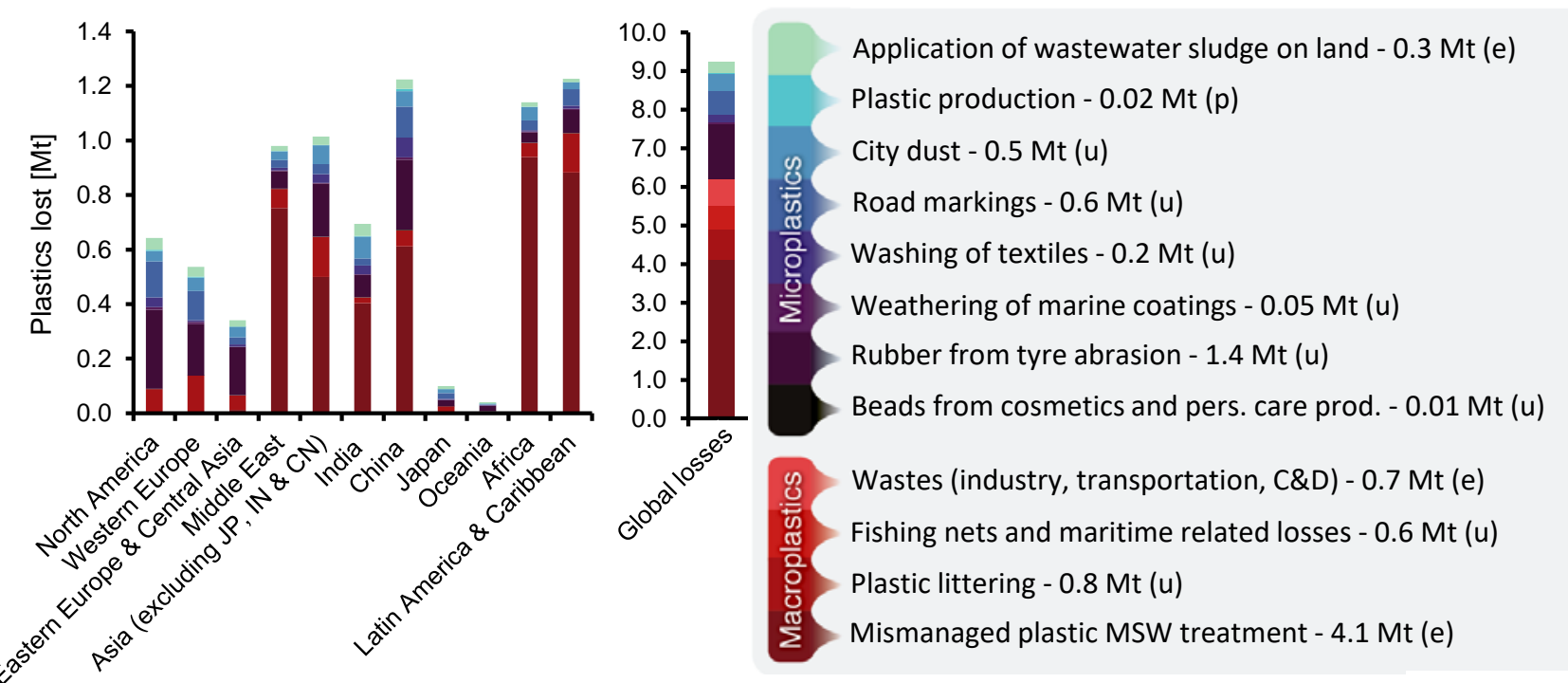

Figure 2 Losses of macroplastics and microplastics to the environment (all marine, freshwater, and terrestrial compartments combined) characterized according to region and loss sources. Losses from maritime activities like fishing or shipping, and losses from building industry and the transportation sector could not be assigned to specific regions and are only indicated in the global estimates. (p) is loss during production stage, (u) is loss during use stage, (e) is loss during end-of-life stage,

The distribution of microplastic polymers lost to the environment is shown in Figure 3. In total, 3.0 Mt of microplastics are lost globally and losses primarily stem from abrasion of polymer-containing products, such as tyres (47\%), road markings (19\%) and city dust (15\%). The geographical distribution of losses related to abrasion of tyres and road markings generally follow the usage distribution of vehicles. The geographical distribution of losses related to city dust is a function of the plastic consumption in the region and the level of wastewater treatment. Our results indicate that the magnitude of microplastic losses from a region is primarily influenced by the total plastic consumption in the region. For instance, North America has the highest loss of microplastics which is driven by comparatively high per-capita plastic consumption (UN Environment, 2018). Washing of synthetic textiles were found to account for about $7.2 \%$ of global microplastics losses and regional distribution is generally a function of consumption of synthetic textiles and removal of microfibers from the 
wastewater. The identified main sources of microplastic losses indicate that the majority of losses are related to indirect losses from use and weathering of plastics. Indeed, losses related to products using microplastics, such as CPCPs are found to only have little contribution to total microplastic loss $(0.4 \%$ of total microplastics loss). In accordance with previous studies, the direct losses of microplastics from plastics production are also found to be low compared to other sources of microplastic losses $(0.8 \%$ of total microplastics loss).
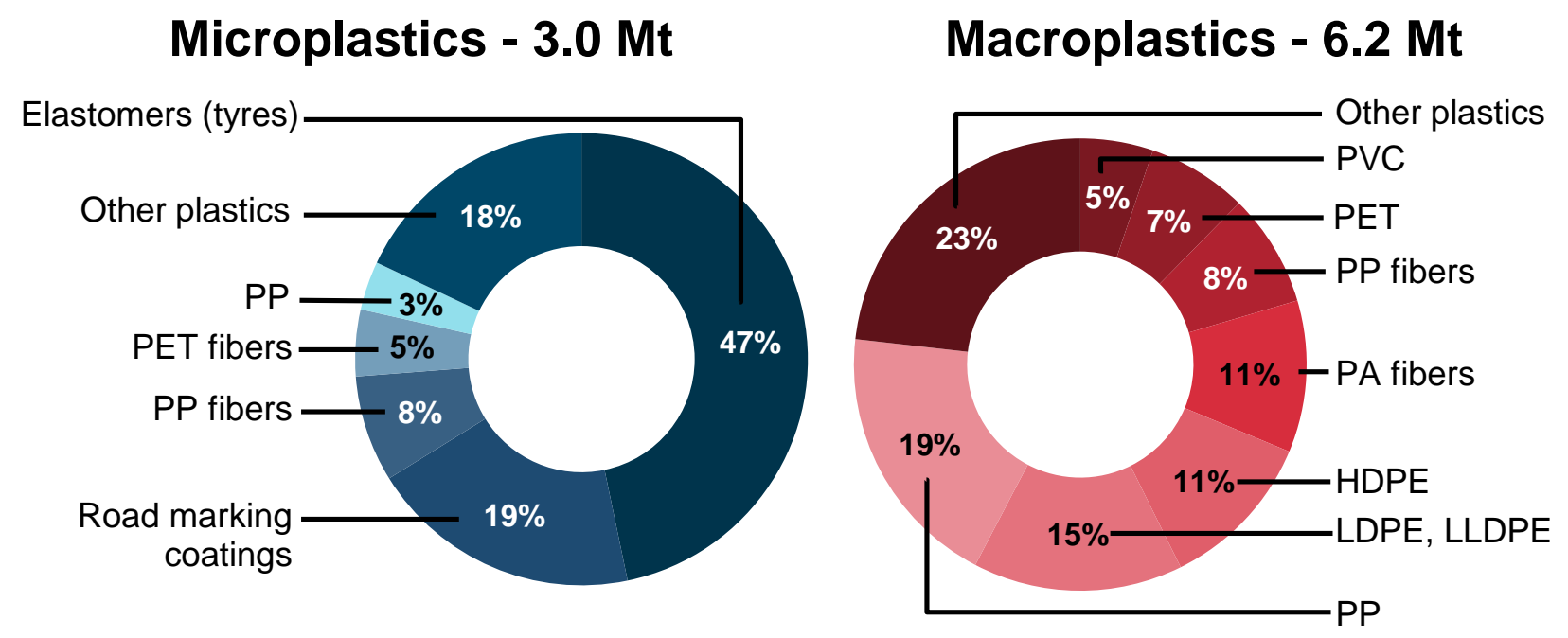

Figure 3 Losses of microplastics and macroplastics to the environment (marine, freshwater, and terrestrial compartments) by polymers and plastic applications (when exact plastic (or polymer) types cannot be identified).

The result of the Monte Carlo simulation is shown in Figure 4. It is apparent that loss estimates are accompanied by significant uncertainties illustrated by the $95 \%$ CI ranging from 4.3 to $23.3 \mathrm{Mt}$ for total plastic losses. The wide range of the total loss is primarily due to uncertainty in the losses from macroplastics while uncertainty of the estimated losses of microplastics is relatively low. The large uncertainty in the estimated macroplastic loss is mainly due to uncertainty about the share of plastics lost from mismanaged waste management as this parameter, by far, had the largest contribution to 
Ryberg, M.W., Hauschild, M.Z., Wang, F., Averous-Monnery, S., Laurent, A., 2019. Global environmental losses of plastics across their value chains. Resour. Conserv. Recycl. 151. https://doi.org/10.1016/j.resconrec.2019.104459

variance (i.e. 3.3; Table S23) with the second largest contributor being the share of plastics in MSW for Latin America \& Caribbean with a contribution to variance of 0.26. Indeed, the importance of this parameter to the final result is also indicated in Figure 5 where the share of mismanaged MSW lost has the strongest influence on the robustness of the global plastic loss estimates with an $\mathrm{S}_{\text {coef }}$ of 0.44 . For microplastics, the total loss estimate was most influenced by the fraction of rubber lost from tyres with a value for $\mathrm{S}_{\text {coef }}$ of 0.15 and a contribution to variance of 0.32 (Figure 5 and Table S23). The second most important parameter for microplastics was the share of microplastic lost from apparel during washing over lifetime with a $\mathrm{S}_{\text {coef }}$ value of 0.03 and a contribution to variance of 0.015 . Thus, uncertainty with regard to lost rubber from tyres is almost exclusively determining the total estimate of losses from microplastics and the spread of the estimate.

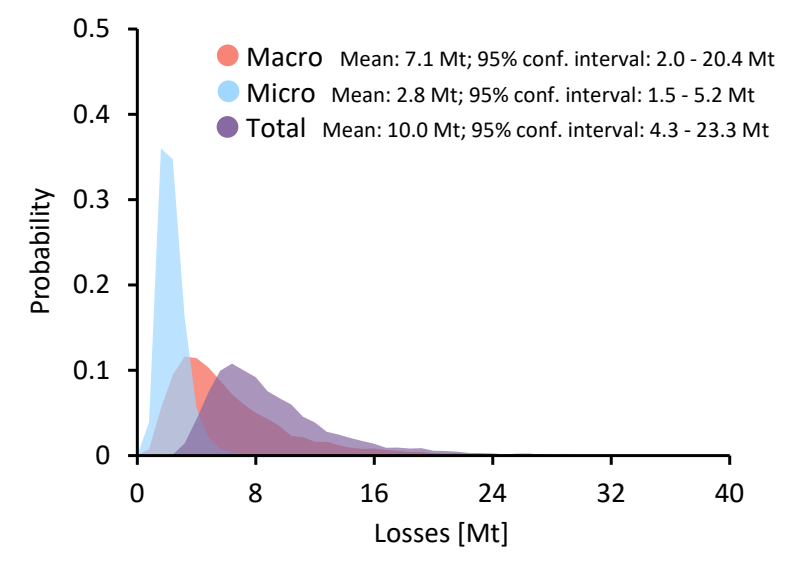

Figure 4 Probability distribution, estimated arithmetic mean and $95 \%$ confidence interval for macroplastics losses, microplastics losses and total plastic losses (global annual estimates). 


\section{Normalized sensitivity coefficients}

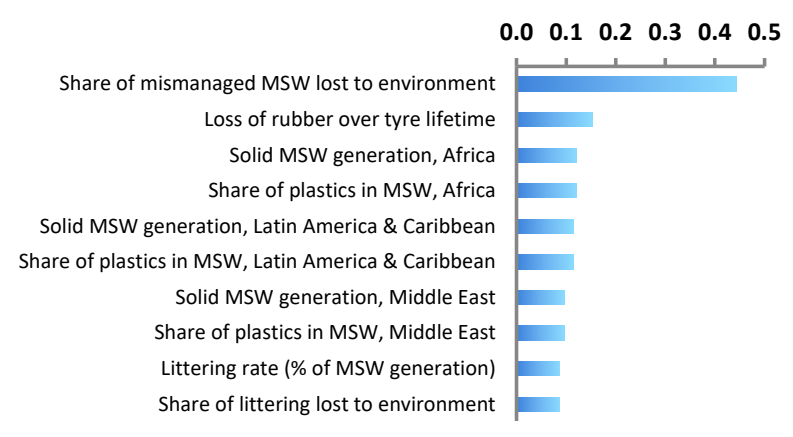

Figure 5 Top 10 parameters to which the estimated total plastic losses to the environment are most sensitive (quantified by a normalized sensitivity coefficient which reflects the change in model output per unit change in model input). All parameters except loss of rubber from tyres (no. 2) relate to macroplastics. See Table S23 for full list of normalized sensitivity coefficients.

\section{Discussion}

\subsection{Comparisons with previous estimates of global plastic losses}

Overall, the comparison with previous estimates demonstrate a relatively good alignment across studies, however, a number of key differences where identified which are addressed in the following. For microplastics, Boucher and Friot (2017) report that between 1.8 and 5 Mt of microplastics are lost to the environment while Sherrington et al. (2016) estimate that 1.1 to $2.9 \mathrm{Mt}$ microplastics are lost to the ocean. The estimates in our study are similar to those by Boucher and Friot (2017) which was expected as there are large similarities in the methods and data used for estimating losses. Our estimates appear large than those by Sherrington et al. (2016) which is likely caused by the inclusion of more loss sources (e.g. wastewater sludge applied on agricultural fields) and because the estimate by Sherrington et al. (2016) only includes ocean losses and it is likely that only a fraction of the total loss to environment will reach the oceans. Similar to Boucher and Friot (2017), we also find that rubber particles from tyre abrasion dominate microplastic losses. However, it is worth noting that this dominance is not reflected by occurrences of tyre elastomers reported in ocean monitoring studies. 
Actually, little is known about the fate and effects of elastomers in the environment (Wik and Dave, 2009). The absence of tyre elastomers in monitoring studies might be due to removal of the elastomers as part of human activities (e.g. wastewater treatment and which we were not able to quantify) or natural processes, e.g. retention in soil and freshwater sediments before reaching the oceans, or because the size of the tyre elastomer particles is below the detection limit of the monitoring equipment. As an addition to previous global loss estimates, we found that microplastic losses related to wastewater treatment and subsequent application of wastewater sludge on agricultural land is an important source of plastic losses. Indeed, the mass of plastics applied to soil amounts to $9.1 \%$ of global losses. Another important finding is that losses related to the use of CPCPs and losses of micro-pellets as part of plastic production are nearly negligible compared to other sources of losses. Similarly to Sherrington et al. (2016), we estimate losses of CPCPs to be about $0.01 \mathrm{Mt}$, but we find that this only corresponds to ca. 0.36\% of total microplastic losses. Thus, although there has been a political focus on plastics in CPCPs (e.g. European Commision, 2019), global losses of plastics to the environment from use of CPCPs do not seem to be of major importance. This should however be considered with caution as this interpretation only relates plastics losses to the environment, and not to their actual damages. A small loss of a given plastics type may have larger environmental damage than a larger quantity of another plastics type -see further details in Section 4.4. Only based on loss quantities, we, therefore, recommend further research to focus more on identifying the largest sources of plastic losses such as tyre elastomers, road markings and city dust.

The estimates losses of macroplastics to the environment from littering and mismanaged waste treatment, i.e. 4.9 Mt with a 95\% CI ranging from 1.4-19.7 Mt, are comparable to the estimate by Jambeck et al. (2015) who reported that between 4.8 and 12.7 Mt of plastic waste generated within 50 $\mathrm{km}$ of the coast are released to the ocean as a result of mismanaged waste systems. The losses 
estimated in this study are bound to be larger as they include global losses to the environment while the losses reported by Jambeck et al. (2015) only cover losses to oceans from coastal areas.

With this in mind, our estimates appear relatively lower than the estimate by Jambeck et al. (2015). This difference is due specific differences in methodology and data. First, we assumed a 10\% loss rate of mismanaged waste, while Jambeck et al. (2015) assumed 15\% to arrive at the estimated 4.8 Mt. Nevertheless, since this share of lost plastics is the most sensitive parameter in the model (Figure 5), we applied a wide probability range for this parameter with a $95 \%$ CI ranging from $5 \%$ to $61 \%$ in our global uncertainty analysis (see Methods section). Hence, it is likely that the 'true' value lies within the $95 \%$ CI of our estimate. Still, more research is needed to reduce the large uncertainty that is currently associated with losses of plastics to the environment and oceans. Secondly, we used updated and more representative data for determining the MSW generation and plastic fraction in the MSW. For example, the mismanaged plastic waste amount in China was reported to be ca. 8.2 Mt (Jambeck et al., 2015). Here, Jambeck et al. (2015) apply a waste generation rate based on the urban Chinese population (i.e. $1.1 \mathrm{~kg} / \mathrm{cap} / \mathrm{day}$ from Hoornweg et al., 2005). In contrast, we based Chinese MSW generation on a statistical model by UN Environment (2018) where MSW generation was estimated on the basis of GDP per capita and the specific region (see SM Section 1.3.1). Here, a MSW generation rate of 0.3 $\mathrm{kg} / \mathrm{cap} / \mathrm{day}$ (i.e. ca. a factor 3 less) was estimated for the total Chinese population. When upscaling to country level, this amount to 6.1 Mt mismanaged waste, thus, a substantial reduction compared to Jambeck et al. (2015), which propagate to important reductions in the estimated total plastic losses.

\subsection{Future research needs for estimating plastic losses}

A number of knowledge gaps still remains to quantify the losses of plastics from the plastic value chain. In the following section, we highlight some of them, where additional research is needed: 
- More knowledge about plastic losses as part of waste management is urgently needed. This was found to be the largest source of plastic losses and also the most sensitive parameter (see Figs. 2 and 5). Yet, the fraction of plastics lost is based on assumptions (Jambeck et al., 2015) and not actual measurements. First, it is important to come to a consensus on the definition of mismanaged waste and what types of plastics waste and fraction such definition should include. This is needed to aid comparability among studies on the losses and among nations where differences in mismanaged waste share might be due to differences in definitions. Secondly, information and data on the extent of mismanaged MSW and other wastes and the associated losses to the environment from mismanaged treatment of MSW and other wastes are needed. Here, the most important factor to investigate appears to be the share of plastic waste that is assumed lost to the environment due to inadequate or mismanaged waste management (Figure 5). More efforts are therefore needed to generate data and models to better characterize this parameter in the modeling of the plastic losses, accounting for the geographical variations in waste generation and disposal practices, e.g. informal and uncontrolled waste management (Horton et al., 2017).

- It was estimated that almost $14 \%$ of total macroplastic losses stem from littering. However, currently there is only one estimate of littering available. Thus, more studies on littering and the associated losses to the environment are needed to get results that better reflects the 'true' value. Furthermore, additional studies on littering should be geographically differentiated and also differentiated into different polymers or at least plastic applications to allow for identifying potentially problematic areas and polymers (UN Environment, 2018).

- There is a need for more knowledge about the plastic losses from different plastic production processes and from handling and transportation of the plastics. This will facilitate more representative estimates of the losses and should allow for accounting for the losses related to the 
production of the different polymer types. However, as the losses from production, handling, and transport of plastics are found to be small relative to other sources of losses, bridging this gap is not considered as important as for example improving the loss estimates related to littering and disposal of plastic MSW or other plastic wastes. Nevertheless, losses associated with production should not be ignored and the losses can be substantial in terms of microplastic concentrations in waters situated in close proximity to plastic production facilities, as shown by Norén (2007), where microplastic concentrations were between two and three orders of magnitude higher.

- There is a need for more knowledge about the process for which losses could not be quantified, such as losses related to agricultural plastics use and floats and similar equipment used in marinas and aquaculture (see Table S22 for a list of the known unknowns). Information about these is particularly important in order to understand whether or not these potential sources of plastics losses are significant sources of plastic losses to the environment.

\section{$\underline{4.3 \text { Needs for reducing environmental losses of plastics }}$}

The results of our study show that the majority of plastic losses are related to the use and disposal of the plastics. Thus, focus should be on reducing losses from these stages. However, this might require substantial changes to other parts of the plastic life cycle such as how we produce and consume plastics (Borrelle et al., 2017). It is argued that to reduce the global problem of marine plastic pollution, holistic integrated measures that involve the entire plastics value chain and different societal actors (such as industry, government, civil society and academia) are needed to tackle this problem (Borrelle et al., 2017; Crippa et al., 2019; UN Environment, 2018; Vince and Hardesty, 2017). 
With regard to waste management, losses are mainly a result of mismanaged waste treatment and a direct means for reducing losses is to improve the waste management system in the regions where the majority of the losses occur. This primarily concerns Africa, the Middle East, Asia and Latin America where waste management systems need major improvements. Cross-border solutions are needed to solve the problem with marine plastic pollution (Borrelle et al., 2017) and the improvement of country scale waste management systems should be a global concern and not be left for the specific countries to solve as these might have other more urgent national needs to address. A suggested option could be to implement an extended producer responsibility program to create a global fund for funding development of better waste management systems in the countries where plastic losses occur (Borrelle et al., 2017).

For the use stage, losses are mainly a result of abrasion and weathering of plastic products. A recommendation for decision-makers in governments and companies is, therefore, to focus on substituting plastics in these products with other materials without instigating increased environmental impacts elsewhere. Alternatively, focus could be on technological improvements in terms of using more durable plastics or ensuring that the microplastics are collected and captured as part of the solid waste or wastewater treatment systems. Similarly to other pollutants, such as heavy metals, it would be relevant to define limit values on the concentrations of microplastics in sewage sludge applied on land. A general recommendation for reducing losses of plastics across the plastics life cycle is to reduce the overall consumption of plastics in society. This can be done either via general reduction in consumption or by substituting plastics with other materials (UN Environment, 2018). For instance, some countries, e.g. Kenya, introduced a ban on plastic bags which drastically reduced consumption of plastics (NEMA, 2017). Other means for reducing consumption could be through encouraging reuse, taxation, and awareness raising campaigns. 
All of these recommendations require that actions are taken and changes in either technology or consumption patterns are made. Along with these actions, we stress the importance of applying a life cycle perspective and assessing whether such changes will overall be environmentally beneficial or lead to a shift or creation of environmental impacts. This can be facilitated with the use of tools such as the ISO-standardised life cycle assessment methodology (Hellweg and Milà I Canals, 2014). Indeed, a reduction in consumption of plastics would likely bring reductions in other environment problems, such as climate change, where a decrease in plastic consumption and, thus, production, would result in less greenhouse gas emissions. However, it might also increase other relevant environmental impacts. For instance, removal of plastics in paint might reduce microplastic losses stemming from abrasion of the paint; but a paint with less or no plastics might have shorter life-time. As a consequence, the surface might have to be painted more frequently leading to production of more paints with additional greenhouse gas emissions. Similarly, if consumption of plastics is reduced, this may shift consumption towards other materials or services which give rise to other environmental impact categories or areas (this is referred to as rebound effects). Hence, as part of decision-making, it is important to comprehensively assess the consequences of the decisions to ensure that the intended actions for reducing marine plastics pollution do not inadvertently increase other environmental impacts.

\subsection{Moving from mass to damage}

The results of this study provide a quantification of the mass input of plastics to the environment. While this allows for identifying the main sources of losses, it does not adequately allow for evaluating the damages that the plastics may cause to ecosystems and human health. For example, a mass of released microplastics will have different and potentially much larger impacts on ecosystems than an 
equal mass of macroplastics due to differences in shape and physicochemical properties. In order to identify and target the polymers, plastic application and sources of losses to the environment that cause the largest problems in the environment, it is essential to mechanistically link the sources of plastic losses to their potential damages to ecosystems and human health. Yet, methods for comprehensively predicting the fate of different plastics (e.g. different plastic applications, polymers, sizes and shapes) in the environment and the exposure of and damages to ecosystems or humans are currently lacking (Crippa et al., 2019). Different studies have separately assessed specific environmental fate pathways (e.g. Besseling et al., 2017; Everaert et al., 2018; GESAMP, 2016; Horton et al., 2017; Koelmans et al., 2017b; Lebreton et al., 2017; Pham et al., 2014) or ecosystem damages from exposure of specific plastics (e.g. Anthony et al., 2015; GESAMP, 2016, 2015; Koelmans et al., 2017a; Rochman et al., 2016; Wik and Dave, 2009), but methods which combine the different methods into a consistent assessment framework starting from loss through fate over exposure and ending with damages to ecosystems and humans are lacking. Developing such a framework should be considered a priority as this will enable robust and science-based assessment and identification of which losses from the plastic value chain pose the largest environmental problems. Moreover, such assessment framework would also allow comparison with other environment impacts, such as climate change and ecotoxicity, to facilitate decision-making with a multi-impact perspective which is needed to avoid unintentionally shifting the burden to other environmental impacts (Laurent and Owsianiak, 2017).

\section{Conclusions}

This study provided a comprehensive estimate of global plastic losses to the environment in 2015 distributed into different polymers and plastic applications. It was found that about 6.2 Mt (CI: 2.0 - 
20.4 Mt) of macroplastics and 3.0 Mt (CI: 1.5 - 5.2 Mt) of microplastics, respectively, were lost to the environment. The main macroplastic loss source was found to be mismanaged MSW management in low-income and lower-middle income countries which accounted for about 4.1 Mt of plastics lost. For microplastics, the major sources were abrasion of tyre rubbers and road markings, and plastics-based city dust. Reductions of plastic losses to the environment requires an integrated approach, which should involve the global society and all actors across the plastics life cycle from production, through consumption to disposal. It is recommended to advance research on determining losses of plastics, in particular from mismanaged waste management. Moreover, development of a comprehensive assessment framework for assessing the potential damage on ecosystems and human health from different plastics and loss sources should be a priority. Such framework is needed to support decisions and actions for curbing the marine plastic problem while avoiding to inadvertently increase other environmental impacts.

\section{Acknowledgements}

The authors acknowledge the support from the Global Environment Facility through the project “Addressing Marine Plastics - A Systemic Approach” (GEF Project ID 9681). We thank J. Sohn for reviewing and proofreading the manuscript. We thank R. Hauschild for design and production of figures.

\section{Appendix A. Supplementary Material}

This Supplementary Material contains extended description of methods used in this study and full list of parameters for the sensitivity and uncertainty analysis. 


\section{References}

Arthur, C., Baker, J., Bamford, H. (Eds.), 2009. Proceedings of the international research workshop on the occurrence, effects and fate of microplastic marine debris. Sept 9-11, in: NOAA Technical Memorandum NOS-OR\&R30. Tacoma, USA.

Auta, H.S., Emenike, C.U., Fauziah, S.H., 2017. Distribution and importance of microplastics in the marine environmentA review of the sources, fate, effects, and potential solutions. Environ. Int. 102, 165-176.

Besseling, E., Quik, J.T.K., Sun, M., Koelmans, A.A., 2017. Fate of nano- and microplastic in freshwater systems: A modeling study. Environ. Pollut. 220, 540-548.

Bonanno, G., Orlando-Bonaca, M., 2018. Ten inconvenient questions about plastics in the sea. Environ. Sci. Policy 85, 146-154.

Borrelle, S.B., Rochman, C.M., Liboiron, M., Bond, A.L., Lusher, A., Bradshaw, H., Provencher, J.F., 2017. Why we need an international agreement on marine plastic pollution. Proc. Natl. Acad. Sci. 114, 9994-9997.

Boucher, J., Friot, D., 2017. Primary Microplastics in the Oceans : a Global Evaluation of Sources. International Union for Conservation of Nature and Natural Resources, Gland, Switzerland.

Brooks, A.L., Wang, S., Jambeck, J.R., 2018. The Chinese import ban and its impact on global plastic waste trade. Sci. Adv. 4, eaat0131.

Browne, M.A., J, U.A., Chapman, M.G., Williams, R., Thompson, R.C., van Franeker, J.A., 2015. Linking effects of anthropogenic debris to ecological impacts. Proc. R. Soc. B Biol. Sci. 282, 20142929.

Carpenter, E.J., Anderson, S.J., Harvey, G.R., Miklas, H.P., Peck, B.B., 1972. Polystyrene Spherules in Coastal Waters. Science 178, 749-750.

Carpenter, E.J., Smith, K.L., 1972. Plastics on the Sargasso Sea Surface. Science 175, 1240-1241.

Christensen, T.H., 1989. Environmental Aspects of Sanitary Landfilling, in: Christensen, T.H., Cossu, R., Stegmann, R. (Eds.), Sanitary Landfilling: Process, Technology, and Environmental Impact. Academic Press.

Cole, G., Sherrington, C., 2016. Study to Quantify Pellet Emissions in the UK. Eunomia Research \& Consulting, Bristol.

Credence Research, 2016. Monoethylene Glycol (Meg) Market By Application (Polyethylene Terephthalate (Peg), Polyester Fiber, Coolants \& Antifreeze) - Growth, Share, Opportunities \& Competitive Analysis, 2015 - 2022 [WWW Document]. URL http://www.credenceresearch.com/report/monoethylene-glycol-meg-market (accessed 11.13.17).

Crippa, M., De Wilde, B., Koopmans, R., Leyssens, J., Muncke, J., A-C, R., Van Doorsselaer, K., 
Ryberg, M.W., Hauschild, M.Z., Wang, F., Averous-Monnery, S., Laurent, A., 2019. Global environmental losses of plastics across their value chains. Resour. Conserv. Recycl. 151. https://doi.org/10.1016/j.resconrec.2019.104459

Velis, C., Wagner, M., 2019. A circular economy for plastics - Insights from research and innovation to inform policy and funding decisions. European Commission, Brussels, Belgium.

Essel, R., Engel, L., Carus, M., Ahrens, R.H., 2015. Sources of microplastics relevant to marine protection in Germany. Umweltbundesamt, Dessau-Roßlau.

ETRMA, 2011. European Tyre \& Rubber Industry Statistics Edition 2011. European Tyre \& Rubber manufacturers association.

ETRMA, 2017. Statistics - Edition 2017. European Tyre \& Rubber Industry.

Eunomia, 2016. Plastics in the Marine Environment. Eunomia Research \& Consulting, Bristol.

European Bioplastics, 2017. Bioplastics market data [WWW Document]. URL http://www.europeanbioplastics.org/market/ (accessed 12.8.17).

European Commision, 2019. European Commission welcomes ECHA's opinion on restricting microplastics intentionally added to products [WWW Document]. URL https://ec.europa.eu/info/news/european-commission-welcomes-echas-opinion-restrictingmicroplastics-intentionally-added-products-2019-jan-30_en (accessed 3.14.19).

Eurostat, 2018. Sewage sludge production and disposal [env_ww_spd] in 2015 [WWW Document]. URL https://ec.europa.eu/eurostat/web/products-datasets/product?code=env_ww_spd (accessed 8.9.18).

Everaert, G., Van Cauwenberghe, L., De Rijcke, M., Koelmans, A.A., Mees, J., Vandegehuchte, M., Janssen, C.R., 2018. Risk assessment of microplastics in the ocean: Modelling approach and first conclusions. Environ. Pollut. 242, 1930-1938.

GESAMP, 2015. Sources, fate and effects of microplastics in the marine environment: a global assessment. IMO/FAO/UNESCO-IOC/UNIDO/WMO/IAEA/UN/UNEP/UNDP Joint Group of Experts on the Scientific Aspects of Marine Environmental Protection. Rep. Stud. GESAMP No. 90.

GESAMP, 2016. Sources, Fate and Effects of Microplastics in the Marine Environment: Part 2 of a Global Assessment. IMO/FAO/UNESCO-IOC/UNIDO/WMO/IAEA/UN/ UNEP/UNDP Joint Group of Experts on the Scientific Aspects of Marine Environmental Protection. Rep. Stud. GESAMP No. 93.

Geyer, R., Jambeck, J.R., Law, K.L., 2017. Production, use, and fate of all plastics ever made. Sci. Adv. 3, e1700782.

Gouin, T., Avalos, J., Brunning, I., Brzuska, K., Graaf, J. De, Kaumanns, J., Koning, T., Meyberg, M., Rettinger, K., Schlatter, H., Thomas, J., Welie, R. Van, Wolf, T., 2015. Use of Micro-Plastic Beads in Cosmetic Products in Europe and Their Estimated Emissions to the North Sea Environment. SOFW J. 141, 40-46. 
Ryberg, M.W., Hauschild, M.Z., Wang, F., Averous-Monnery, S., Laurent, A., 2019. Global environmental losses of plastics across their value chains. Resour. Conserv. Recycl. 151. https://doi.org/10.1016/j.resconrec.2019.104459

Grand View Research, 2015. Adhesives and Sealants Market Analysis By Technology (Water-based, Solvent-based, Hot Melt, Reactive), By Product (Acrylic, Polyurethane, Polyvinyl Acetate (PVA), Epoxy, EVA), By Application (Pressure Sensitive, Construction, Automotive, Packaging, Furnit [WWW Document]. URL https://www.grandviewresearch.com/industry-analysis/adhesives-andsealants-market (accessed 1.4.18).

Haward, M., 2018. Plastic pollution of the world's seas and oceans as a contemporary challenge in ocean governance. Nat. Commun.

Hellweg, S., Milà I Canals, L., 2014. Emerging approaches, challenges and opportunities in life cycle assessment. Science 344, 1109-1114.

Hoornweg, D., Bhada-Tata, P., 2012. What A Waste. A Global Review of Solid Waste Management, World Bank Urban Development Series Knowledge Papers. The World Bank, Washington, DC.

Hoornweg, D., Lam, P., Chaudhry, M., 2005. Waste management in China: Issues and recommendations, East Asia. The World Bank, Washington.

Horton, A.A., Walton, A., Spurgeon, D.J., Lahive, E., Svendsen, C., 2017. Microplastics in freshwater and terrestrial environments: Evaluating the current understanding to identify the knowledge gaps and future research priorities. Sci. Total Environ. 586, 127-141.

Jambeck, J.R., Geyer, R., Wilcox, C., Siegler, T.R., Perryman, M., Andrady, A., Narayan, R., Law, K.L., 2015. Plastic waste inputs from land into the ocean. Science 347, 768-771.

Jerven, M., 2014. On the accuracy of trade and GDP statistics in Africa: Errors of commission and omission. J. African Trade 1, 45-52.

Kawecki, D., Scheeder, P.R.W., Nowack, B., 2018. Probabilistic Material Flow Analysis of Seven Commodity Plastics in Europe. Environ. Sci. Technol. 52, 9874-9888.

Koelmans, A.A., Besseling, E., Foekema, E., Kooi, M., Mintenig, S., Ossendorp, B.C., RedondoHasselerharm, P.E., Verschoor, A., Van Wezel, A.P., Scheffer, M., 2017a. Risks of Plastic Debris: Unravelling Fact, Opinion, Perception, and Belief. Environ. Sci. Technol. 51, 11513-11519.

Koelmans, A.A., Kooi, M., Law, K.L., Van Sebille, E., 2017b. All is not lost: Deriving a top-down mass budget of plastic at sea. Environ. Res. Lett. 12.

Kumar, S., Bhattacharyya, J.K., Vaidya, A.N., Chakrabarti, T., Devotta, S., Akolkar, A.B., 2009. Assessment of the status of municipal solid waste management in metro cities, state capitals, class I cities, and class II towns in India: An insight. Waste Manag. 29, 883-895.

Lassen, C., Hansen, S.F., Magnusson, K., Hartmann, N.B., Rehne Jensen, P., Nielsen, T.G., Brinch, A., 2015. Microplastics: Occurrence, effects and sources of releases to the environment in Denmark. Danish Environmental Protection Agency, Copenhagen.

Laurent, A., Owsianiak, M., 2017. Potentials and limitations of footprints for gauging environmental 
Ryberg, M.W., Hauschild, M.Z., Wang, F., Averous-Monnery, S., Laurent, A., 2019. Global environmental losses of plastics across their value chains. Resour. Conserv. Recycl. 151. https://doi.org/10.1016/j.resconrec.2019.104459

sustainability. Curr. Opin. Environ. Sustain. 25, 20-27.

Lebreton, L.C.M., Van Der Zwet, J., Damsteeg, J.W., Slat, B., Andrady, A., Reisser, J., 2017. River plastic emissions to the world's oceans. Nat. Commun. 8, 1-10.

MacArthur, E., 2017. Beyond plastic waste. Science 358.

Maddah, H.A., 2016. Polypropylene as a Promising Plastic: A Review. Am. J. Polym. Sci. 6, 1-11.

Magnusson, K., Eliasson, K., Fråne, A., Haikonen, K., Hultén, J., Olshammar, M., Stadmark, J., Voisin, A., 2016. Swedish Sources and Pathways for Microplastics to the Marine Environment. Swedish Environmental Protection Agency, Stockholm.

Mehlhart, G., Blepp, M., 2012. Study on land-sourced litter (LSL) in the marine environment: review of sources and literature. Öko-Institut e.V., Darmstadt / Freiburg.

Mian, M.M., Zeng, X., Nasry, A. al N. Bin, Al-Hamadani, S.M.Z.F., 2017. Municipal solid waste management in China: a comparative analysis. J. Mater. Cycles Waste Manag. 19, 1127-1135.

NEMA, 2017. Ban on plastic carrier bags. National Environment Management Authority (Kenya).

Norén, F., 2007. Mikroskopiska plastpartiklar i Västerhavet, en pilotstudie över förekomst. KIMO Sverige.

Pham, C.K., Ramirez-Llodra, E., Alt, C.H.S., Amaro, T., Bergmann, M., Canals, M., Company, J.B., Davies, J., Duineveld, G., Galgani, F., Howell, K.L., Huvenne, V.A.I., Isidro, E., Jones, D.O.B., Lastras, G., Morato, T., Gomes-Pereira, J.N., Purser, A., Stewart, H., Tojeira, I., Tubau, X., Van Rooij, D., Tyler, P.A., 2014. Marine Litter Distribution and Density in European Seas, from the Shelves to Deep Basins. PLoS One 9, e95839.

plastemart, 2010. Polyamide growth to slow to 3\% from 2009 until 2014 [WWW Document]. URL http://www.plastemart.com/plastic-technical-articles/IR-pigments-reflect-solar-radiation-andkeep-polymer-products-cooler/1363 (accessed 11.13.17).

PlasticsEurope, 2016a. Plastic - the Facts 2016. PlasticsEurope.

PlasticsEurope, 2016b. Plastics Europe. PlasticsEuropeMarket Research Group (PEMRG) / ConsulticMarketing \& IndustrieberatungGmbH.

PlasticsEurope, 2017. PlasticsEurope Operation Clean Sweep - Report 2017. PlasticsEurope.

prnewswire, 2015. Global Thermosetting Plastics Market - Segmented by Type, Industry and Geography - Trends and Forecasts (2015-2020) - Reportlinker Review [WWW Document]. URL https://www.prnewswire.com/news-releases/global-thermosetting-plastics-market---segmentedby-type-industry-and-geography---trends-and-forecasts-2015-2020---reportlinker-review300145372.html (accessed 1.4.18).

Rochman, C.M., Browne, M.A., Underwood, A.J., van Franeker, J.A., Thompson, R.C., Amaral- 
Zettler, L.A., 2016. The ecological impacts of marine debris: unraveling the demonstrated evidence from what is perceived. Ecology 97, 302-312.

Ryberg, M.W., Owsianiak, M., Laurent, A., Hauschild, M.Z., 2015. Power generation from chemically cleaned coals: do environmental benefits of firing cleaner coal outweigh environmental burden of cleaning? Energy Environ. Sci. 2435-2447.

Schmidt, C., Krauth, T., Wagner, S., 2017. Export of Plastic Debris by Rivers into the Sea. Environ. Sci. Technol. acs.est.7b02368.

Sherrington, C., Darrah, C., Hann, S., Cole, G., Corbin, M., 2016. Study to Support the Development of Measures to Combat a Range of Marine Litter Sources. Report for European Commision DG Environment. Eunomia Research \& Consulting, Bristol.

Sinograce chemical, 2017. Global coating emulsion polymer in 2020 will reach 5 million tons [WWW Document]. URL http:/www.sinogracechem.com/blog/global-coating-emulsion-polymer-in2020-will-reach-5-million-tons_b14 (accessed 1.4.18).

Sundt, P., Schulze, P.-E., Syversen, F., 2014. Sources of microplastic- pollution to the marine environment. Miljødirektoaret/Norwegian Environment Agency.

UN Environment, 2018. Mapping of global plastic value chain and plastic losses to the environment (with a particular focus on marine environment). United Nations Environment Programme, Nairobi, Kenya.

UNEP, 2016. Marine Plastic Debris and Microplastics - Global Lessons and Research to Inspire Action and Guide Policy Change. United Nations Environment Programme, Nairobi, Kenya.

United Nations, 2018. Global indicator framework for the sustainable development goals and targets of the 2030 agenda for sustainable development. Work Stat Comm Pertain to 2030 Agenda Sustain Dev 1-21.

Vince, J., Hardesty, B.D., 2017. Plastic pollution challenges in marine and coastal environments: from local to global governance. Restor. Ecol.

Vose Software, 2016. Vose ModelRisk.

Wik, A., Dave, G., 2009. Occurrence and effects of tire wear particles in the environment - A critical review and an initial risk assessment. Environ. Pollut. 157, 1-11.

Yeh, W.W.-G., 1986. Review of Parameter Identification Procedures in Groundwater Hydrology: The Inverse Problem. Water Resour. Res. 22, 95-108. 